\author{
Military Technical College \\ Kobry El-Kobbah, \\ Cairo, Egypt.
}

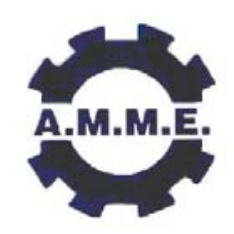

\title{
EFFECT OF TITANIUM, MOLYBDENUM AND MANGANESE ON WEAR BEHAVIOUR OF HIGH CHROMIUM CAST IRON
}

\author{
$13^{\text {th }}$ International Conference \\ on Applied Mechanics and \\ Mechanical Engineering.
}

\author{
BOUHAMLA* K., MAOUCH ${ }^{* *}$ H. and HADJI** A.
}

\begin{abstract}
High chromium cast irons are widely used in many engineering practices where wear resistance is required. This paper studies the effect of titanium concentration on the wear behaviour of slightly hypoeutectic high chromium white cast iron. Other approach was investigated by adding other carbide forming elements such as manganese and molybdenum as a combination of two and three elements. The aim is mainly to see the influence of these elements on the toughness of the matrix, the smoothness of the structure as well as the wear properties of this kind of cast iron. Results, discussed in terms of the wear behaviour, shows that lower volume loss is seen for the sample having higher titanium content $(3 \% \mathrm{Ti})$. This explains that titanium proeutectic carbide is the first phase precipitation during solidification which contributes to a reinforcement of the matrix. The formation of these carbides consumes parts of the carbon present in the alloy so that during eutectic solidification the volume of eutectic carbides diminished. The addition of manganese and molybdenum gives less important results.
\end{abstract}

\section{KEY WORDS}

Chromium cast iron, carbides, wear, eutectic.

\footnotetext{
** Iron and Steel Applied Research Unit, Annaba, Algeria.

Graduate student, Foundry Laboratory, Badji-Mokhtar University, Annaba, Algeria.

*** Professor, Foundry Laboratory, Badji-Mokhtar University, Annaba, Algeria.
} 


\section{INTRODUCTION}

Wear resistance is an important characteristic to be taken into account when we have to produce a cast iron suited for abrasion resistance applications. Many researches based on alloying elements addition were investigated in order to improve this material's mechanical strength and wear resistance [1-5]. High chromium cast irons are widely used in engineering practices such as mining, coal and cement industries. They contain hard carbides which can be precipitated as proeutectic and/or eutectic carbides during solidification. These carbides have significant influences on the abrasion behaviour. Other carbides, named secondary carbides can also precipitate during secondary hardening. Research [6] confirms that these carbides are obvious after heat treatment and they are precipitated from the austenite matrix.

So far, much investigation on influence of titanium on high chromium cast iron has been carried out only with an amount of titanium between 0 and $2 \%$ [7]. These published researches indicate that in the composition rang $(0-0.38 \% \mathrm{Ti})$ maximum hardness and abrasion resistance were obtained in a cast iron containing $15 \% \mathrm{Cr}$, $3 \%$ Mo and an amount of carbon about of $2.5 \%$. These additions causes a $30 \%$ increase in the abrasion resistance with respect to the as cast titanium white cast iron.

Researches carried out on the effect of titanium on the wear behaviour of high chromium cast iron have not taken in account the effect combined of titanium with other carbide forming additions [7-10]. The aim of this purpose was to investigate the wear behaviour of high chromium cast iron alloyed with titanium, manganese and molybdenum. The main focus has been an addition of 0.5 to $3 \% \mathrm{Ti}, 0.5 \%$ (Ti+Mo), $0.5 \%(\mathrm{Ti}+\mathrm{Mn})$ and $0.5 \%(\mathrm{Ti}+\mathrm{Mn}+\mathrm{Mo})$. All theses elements are carbides forming element.

\section{EXPERIMENTAL PROCEDURE (DETAILS)}

\section{Melting and Casting}

Samples were cast in a laboratory induction melting furnace. The melt was pored into sand moulds fig.1. In this melting several additions of carbide forming elements was carried out. The amount of $\mathrm{Ti}$ was varied between 0 and $3 \%$, than a combination of $(\mathrm{Ti}+\mathrm{Mn}),(\mathrm{Ti}+\mathrm{Mo})$ and $(\mathrm{Ti}+\mathrm{Mn}+\mathrm{Mo})$ was added to the melting of an amount about of $0.5 \%$ for each one. The test samples used for wear resistance and metallographic characterization are sectioned from the castings. The chemical composition of the basic white cast iron is listed in Table1.

\section{Metallographic Examination}

For metallographic examination, samples were prepared using 220-1200 mesh emery paper and polished using $3 \mu \mathrm{m}$ diamond paste. Following the polishing operation, they were etched in $4 \%$ nital solution in order to distinguish the phase clearly. Optical metallography was performed on the studied simples in the as cast state and after heat treatment using LEIKA optical device. 


\section{Heat Treatment}

All the test samples are austenitized at $980^{\circ} \mathrm{C}$ than air quenched to room temperature. Subsequently, they are tempered at $250^{\circ} \mathrm{C}$ followed by air cooling to ambient temperature

\section{Wear Tests}

\section{Abrasion test}

Abrasion tests wear performed with a laboratory apparatus. The details of this experimental rig are shown in fig.2. This technique consists in putting samples in a crusher with some siliceous sand to increase the rate of the wear. The weigh loss is measured every 5 minutes of interval during 15 minutes

\section{Friction test}

This test was realised in order to simulate the wear phenomena witch take place in industrial scale. Wear tests were carried out on pin-on disk of wear testing apparatus shown schematically in fig. 3 . The tests were carried out against 120 quartz disk at $120 \mathrm{rev} / \mathrm{mn}$ at constant speed and under a load of $0.5 \mathrm{Kgf}$ with a travel of $40 \mathrm{~m}$. After the specimen were weighed using a digital scale to determine the weigh loss.

\section{RESULT AND DISCUSSION}

\section{Metallography}

In the as cast state, the microstructure of the base cast iron is mainly composed of a large shaped austenitic matrix surrounded by a eutectic carbide (Fig.4a). Being a hypoeutectic alloy, solidification starts with the formation of prior austenite than finished with the eutectic transformation and the aggregate (austenite $+M_{7} C_{3}$ ) is developed. After heat treatment, such as air hardening and tempering, the matrix still austenitic but the carbide volume fraction appears important comparatively to the as cast state (Fig.4.b). Secondary fine carbides precipitate in the matrix. The chromium content of the matrix decreased and caused a coarsening of $\mathrm{M}_{7} \mathrm{C}_{3}$ type carbides as expected after heat treatment. After tempering no change were evident in the microstructure (Fig.4.b).

Figures 5.a to 5.1 shows the microstructural evolution as the amount of titanium increases in the studied alloy, at the as cast state and after heat treatment, from 0 to $3 \%$. Titanium is a strong carbide forming element and refine the microstructure of hypoeutectic high chromium cast iron.

Comparing to the iron base, varying titanium between 0.5 and $3 \%$, contributes to a refinement of the structure morphology. The eutectic appears in a lengthened shape embedded in an austenitic matrix. The structures exhibits a more refinement with the increase of the titanium amount. The finest structures are obtained after heat treatment where secondary carbides may precipitate and contribute to $a$ strengthening of the matrix. 
The addition of titanium in the experimented cast iron has induced a structural change with various distributions of the structural constituents. The increase of the amount of titanium causes refinement of the secondary dendrites arms spacing of austenite. This is attributed to the precipitation of $\mathrm{TiC}$ particles when the alloy still liquid.

Figures $6 \mathrm{a}$ and $6 \mathrm{~b}$ shows an optical micrograph of casting with $0.5 \% \mathrm{Ti}$ and $0.5 \% \mathrm{Mn}$ in the as cast and treated states. They consist of high eutectic proportion. After heat treatment, manganese and titanium addition causes a refinement of the structure. The titanium and the manganese do not practically have act on the matrix of the cast iron but contributed to a precipitation of a eutectic in a higher proportion around the austenitic grain. Parts of titanium and manganese are dissolved in the matrix and the rest contribute to $\mathrm{M}_{7} \mathrm{C}_{3}$ carbide formation. The structure of the cast iron considerably became refined due to heat treatment and the effect of carbide forming element.

White cast iron containing $0.5 \%(\mathrm{Ti}+\mathrm{Mo})$ also exhibits a refined matrix. The presence of molybdenum with titanium strongly refined and changed the shape of the structural constituents. In the microstructure 6.d two types of austenite are observed, one is granular and the other is dendritic. After heat treatment the structure obtained is more refined (Fig.6.e). This is due to precipitation of secondary carbides in the matrix. In the treated state, the structure became refined and the eutectic appears uniformly distributed around the austenite. Note that secondary carbides can not be discerned by optical microscopy, they appear in very fine scale after heat treatment.

The structure of the cast iron containing $0.5 \%$ (Ti-Mo-Mn) is similar to that of the previous cast iron but with a slight refinement (Fig.7a). In the treated state (Fig. 7b), the combination of these three elements facilitated a formation of a structure consisted of a eutectic better distributed than in the basic cast iron. The volume of the granular austenite increased with regard to that having a dendritic shape. Dendrites of austenite in that case are less lengthened. The treated state with this cast iron allowed to a refinement of the structural constituents as well as the austenite and the eutectic.

\section{Abrasion}

The results on abrasion, for the as cast and treated state are shown in Figs. 8a and $8 \mathrm{~B}$. The heat treated sample of high chromium cast iron has shown a decrease of weigh loss with the increase of the amount of titanium. Affecting a change in titanium content from 0 to $3 \%$ in the studied high chromium cast iron, record decrease of abrasion loss. This is mainly due to the increase of the carbide fraction in the matrix after heat treatment and automatically to an increase of hardness. Before heat treatment all the samples alloyed with titanium exhibits a higher weigh loss. After heat treatment, the precipitation of secondary carbides of $M C$ and $M_{7} C_{3}$ type causes an increase of wear resistance. This can be explained by the fact that in high chromium white cast iron, matrix structure holds the hard eutectic and secondary hard carbides in their place during wear. When this matrix is worn away, the remaining carbides are fractured under stress. The best weigh loos by abrasion is given by the high chromium cast iron containing $3 \% \mathrm{Ti}$. 


\section{Friction}

The data on wear friction for the as cast and heat treated samples are shown in fig.9.a and 9.b. The best weigh losses are obtained with samples combined with 0.5 $\%(\mathrm{Ti}+\mathrm{Mn})$ and $0.5 \%(\mathrm{Ti}+\mathrm{Mn}+\mathrm{Mo})$. The best results still that given by abrasion. The weight of material removed by abrasion is better than that removed by friction and high level of titanium has not given the same result as abrasion tests. The increase of titanium does not affect the friction behaviour of this high chromium cast iron. It means that abrasion and friction process does not occur similarly. All the manganese and the most part of titanium and molybdenum are dissolved in austenite matrix, their beneficial effect was improving friction wear of high chromium cast iron alloyed with Titanium, manganese and molybdenum $f$ the amount of $0.5 \%$ each one. This explains that during friction wear high chromium cast iron alloyed to titanium, manganese and molybdenum of the amount of $0,5 \%$ each one, gives acceptable results.

\section{CONCLUSION}

Characterisations carried out on high chromium cast iron have shown that addition of strong carbide forming element affects positively the microstructure. Results obtained shows that in the as cast state the microstructure is mainly composed of an austenitic matrix and a netted eutectic witch still unchanged after heat treatment. So after heat treatment the matrix was not affected but a change of the eutectic shape was observed. This is due to the depletion of alloying element and carbon.

Abrasion and friction resistance may be increased by increasing the carbide volume fraction in the alloys. Samples with 3\% Ti have given the smaller abrasion loos. Friction results are different from that given by abrasion, abrasion and friction behaviour does not take place of the same way. The best results were obtained after heat treatment with samples alloyed with $3 \%$ titanium

\section{REFERENCES}

[1] Kishore, P. Sampathkuraman, S. Seetharamu, Wear 259 (2005) 70-700.

[2] Cemil cetinkaya, Material and Design 27 (2006) 437-445.

[3] A. Bedolla - Jacuinde, W. M. rainforth, Wear 250 (2001) 449-4461.

[4] C. P. Tabrett, I. R. Sare, Wear 203-204 (1997) 206-219.

[5] Joe H. Tylcgak, Jeffery A. Awk, Rick D. Wilson, Wear 225-229 (1999) 10591069.

[6] K. Kuyucak, R. Llewellyn, AFS Transaction (2006) 1-23.

[7] M. M; Arikan, H. Cimenogli, E. S. Kayali, Wear 247 (2001) 231-235.

[8] Xiaojun $\mathrm{Wu}$, Jiandong Xing, Hanguang $\mathrm{Fu}$, Xiaohui Zhi, Material Science \& engineering A 457 (2007) 180-185.

[9] A. Bedolla-Jacuinde, R. correa, J. G. Quezada, C. Maldonado, Matreial Science \& Engineering A 398 (2005) 297-308.

[10] Xiaohui Zhi, Jiandong Xing, Hanguang FU, Yiming Gao, Materials Charachterization 2007. 
Table 1. Chemical composition of high chromium cast iron

\begin{tabular}{c|c|c|c|c|c|c} 
& & & & \\
$\mathrm{C}, \%$ & $\mathrm{Si}, \%$ & $\mathrm{Mn}, \%$ & $\mathbf{P}, \%$ & $\mathrm{~S}, \%$ & $\mathrm{Cr}, \%$ & Mo, \% \\
\hline 2,31 & 0,87 & 0,77 & $\mathbf{0 , 0 8}$ & $\mathbf{0 , 0 3 1}$ & $\mathbf{1 5 , 0 1}$ & $\mathbf{0 , 0 2}$
\end{tabular}

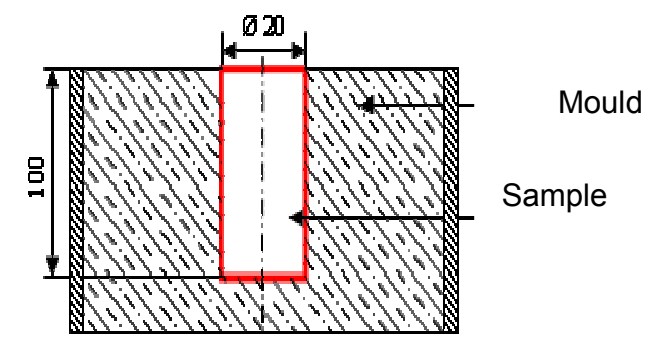

Fig 1. Device for casting samples.

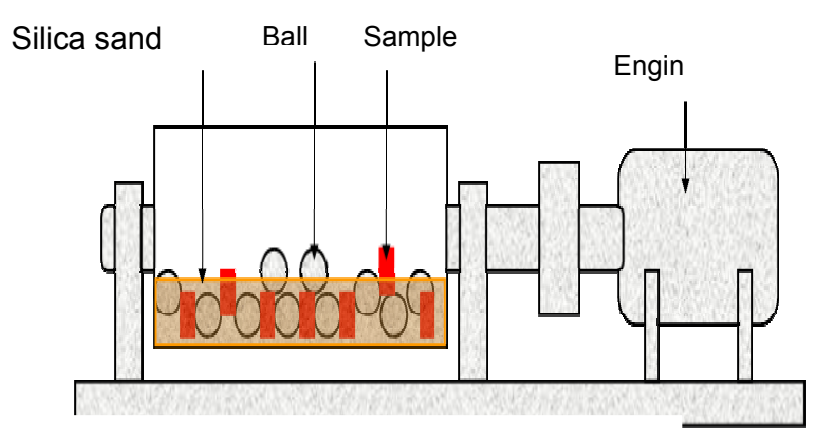

Fig 2. Device for abrasion test

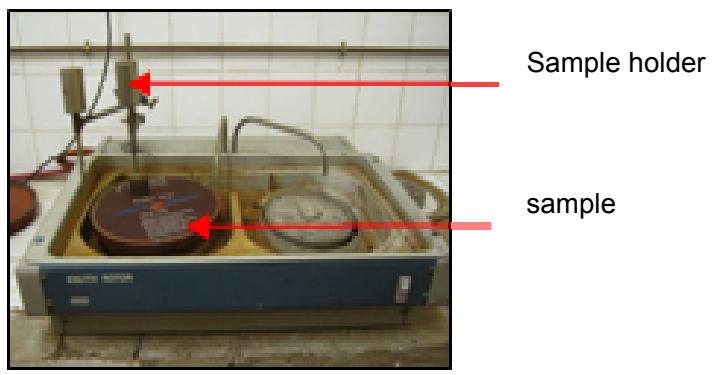

Fig 3. Device for friction test 


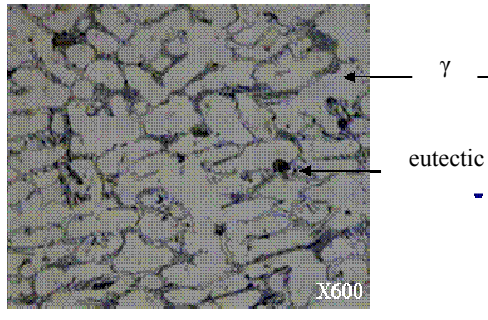

a

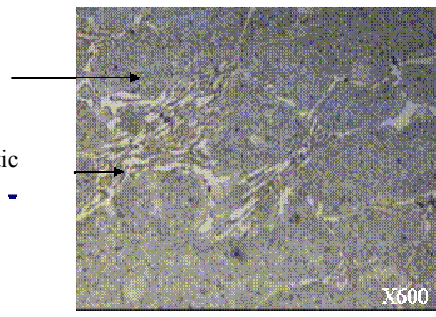

$\mathrm{b}$

Fig.4. Microstructures of base iron. a: as cast state; b Treated

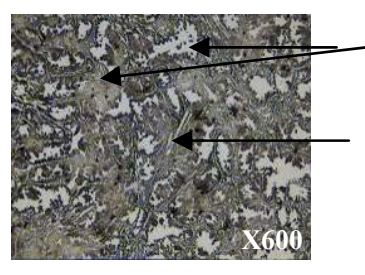

5.a

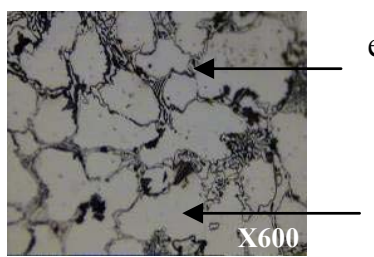

5.e

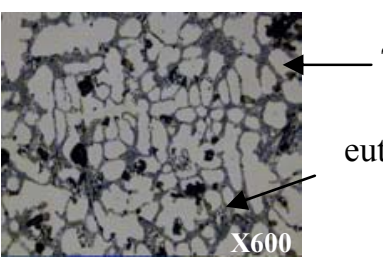

$5 . \mathrm{i}$

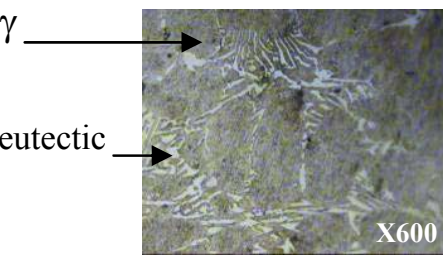

$5 . b$

$0.5 \% \mathrm{Ti}$

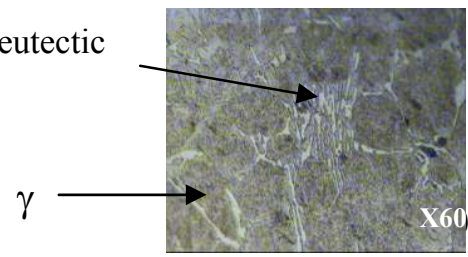

$1.5 \% \mathrm{Ti}$

5.f.

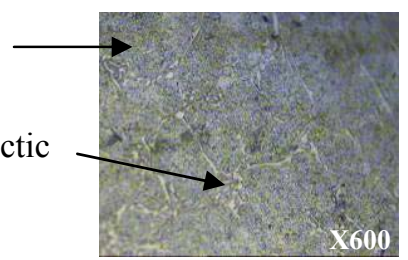

$5 . \mathrm{j}$

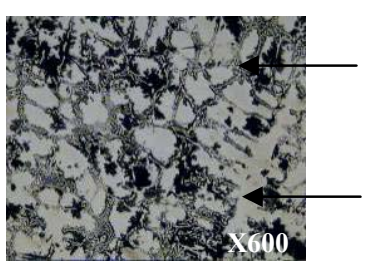

5.c

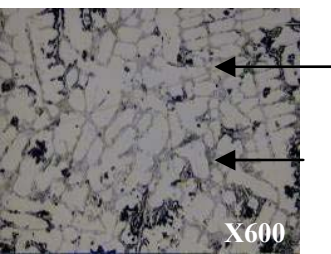

$5 . \mathrm{g}$

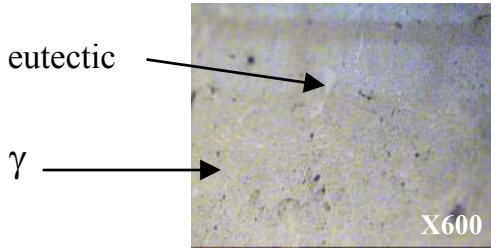

$1 \% \mathrm{Ti}$

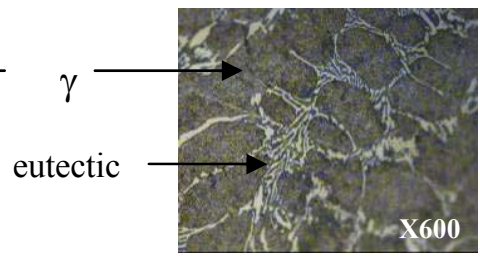

$2 \% \mathrm{Ti}$

5.h

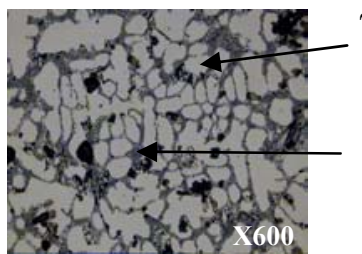

5.k

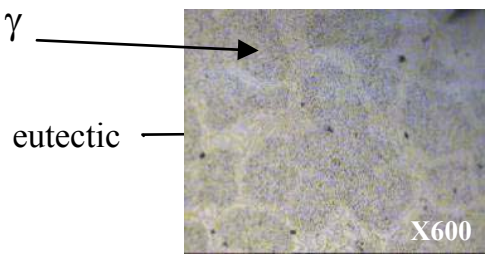

5.1

$2.5 \% \mathrm{Ti}$

$3 \% \mathrm{Ti}$

5. Microstructure of high chromium cast iron alloyed. (a) as cast iron, (b) treated
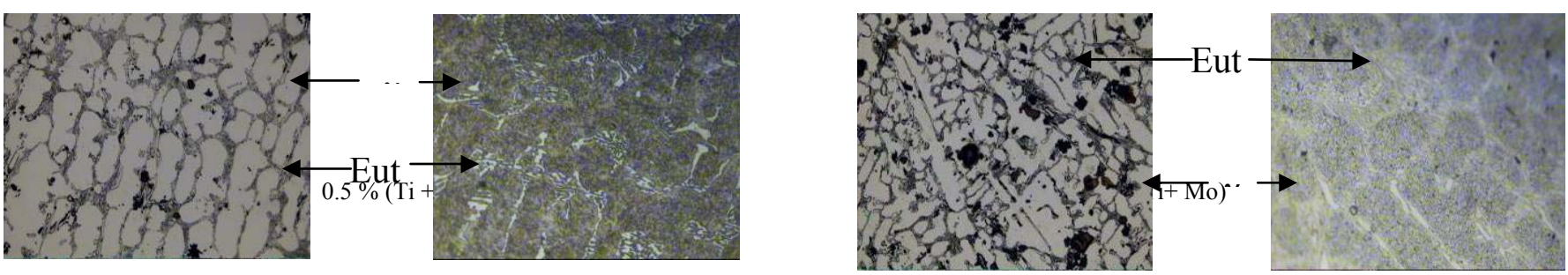

Fig.6. Microstructure of high chromium cast iron alloyed with $0.5 \%(\mathrm{Ti}+\mathrm{Mn})$ and $0.5 \%(\mathrm{Ti}+\mathrm{Mo}) ;(\mathrm{a})$ as cast iron, (b) treated 


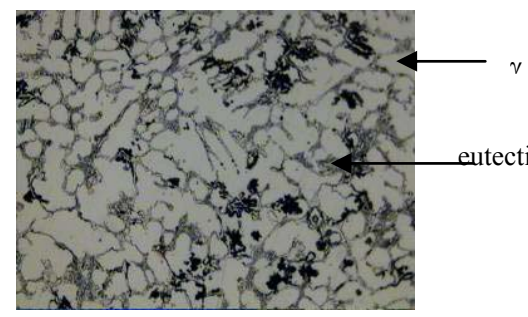

7.a

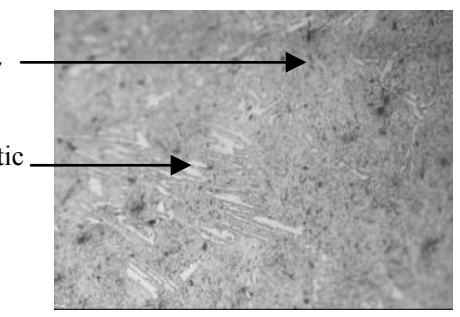

7.b

Fig.7. Microstructure of high chromium cast iron alloyed with $0.5 \%(\mathrm{Ti}+\mathrm{Mn}+\mathrm{Mo}), 7 . \mathrm{a}$ : as cast iron; $7 . \mathrm{b}$ : heat treated.
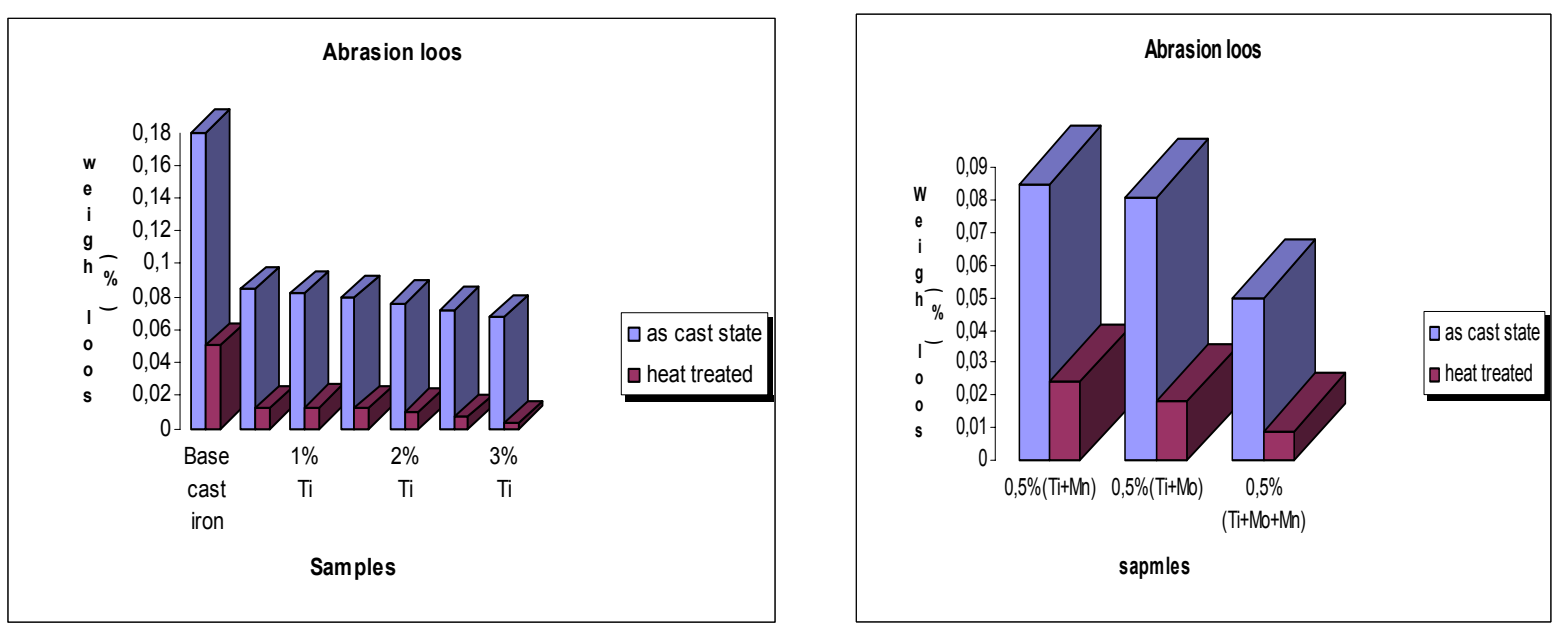

Fig.8. Abrasion loos of studied simples; 8.a: cast iron with different amount of titanium; 8.b: cast iron combined to different alloying elements
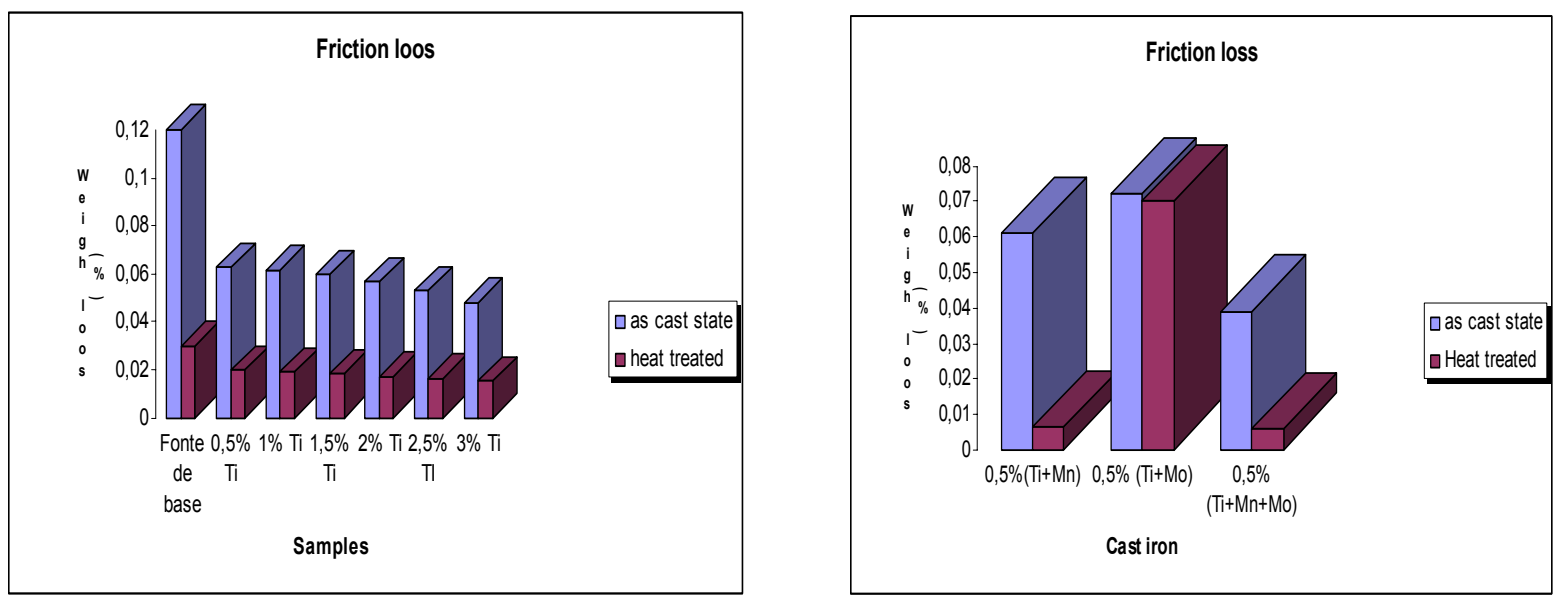

Fig.9. Friction loos of studied simples; 9.a: cast iron with different amount of titanium; 9.b: cast iron combined to different alloying elements 